\title{
Design and Implementation of Laser Rangefinderfor Obstacle Height Monitoring on Line of Sight of Microwave Communication Link
}

\author{
Hudiono*, Mochammad Taufik, Ridho Hendra Yoga P., MartonoDwi Atmadja \\ Department of Electrical Engineering, Politeknik Negeri Malang, \\ Malang, East Java, Indonesia
}

\begin{abstract}
A laser rangefinder is a device that uses laser light to determine the distance of an object. The working principle of this laser rangefinder is that the laser beam that is emitted to the object will be reflected back to the rangefinder, and the required propagation time of laser beam will be calculated to get the distance value. In this study, a laser rangefinder system was designed to be used as monitoring of obstacle height between the line of sight of a microwave communication link using a quadcopter, which is used as a top-viewer picture taker. The quadcopter was used as a device to carry the laser rangefinder to measure the obstacle height between the location points of near-end and farend. The obstacle height reading results were transmitted using a $5.8 \mathrm{GHz}$ wireless transceiver to the monitoring location in real time. The data received were then processed to be displayed in the form of obstacle height graph as a function of the line of sight communication distance. The test results show that the implementation of laser rangefinder technology has an accuracy of more than $90 \%$.
\end{abstract}

Keywords: Line of Sight, Laser Rangefinder, Near-end and far-end, Quadcopter, Obstacle

\section{INTRODUCTION}

The standard operating procedure for a microwave radio transmission survey is by manually determining the location point of nearend and far-end coordinates, then proceed with scanning the communication path to measure the height of the object, which could be an obstacle to the communication system. The obstacle height measurement data are analyzed using the Pathloss software to determine the antenna height position at both near-end and far-end locations so that the communication pathline of sight is free of obstacles [1].

The survey of the microwave transmission system cannot be carried out if the communication trajectory traverses an area that cannot be reached by the transportation system so that the determination of the antenna height can only be done based on the estimated height of the object. This estimation method is susceptible to errors so that a recommendation for the incorrect device installation is often generated.

Thisstudy aimed to design and implement a laser rangefinder device for high-object monitoring systems on a microwave line of sight communication using a quadcopter that

Correspondence address:

Hudiono

Email : hudiono@polinema.ac.id

Address : Jl. Soekarno Hatta No.09, Jatimulyo, Kec. Lowokwaru, Kota Malang, Jawa Timur 65141 movedbetween two candidate points of the antenna location (between the communication lines). The quadcopter was equipped with a Laser Rangefinder as an object height sensor below the communication path.

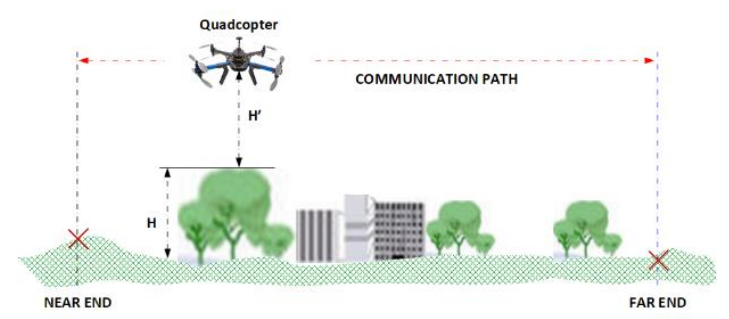

Figure 1. The obstacle height monitoring system

The height measurement results of objects which were suspected as candidate obstacle were sent through a $5.8 \mathrm{GHz}$ wireless transceiver to the monitoring location using a computer. The data was then processed and displayed in real time in the form of a graph.

The automatically received obstacle height data were also stored on the computer. With the help of the Pathloss software, the data were analyzed directly as a basis for determining the antenna height at both near-end and far-end locations so that the line of sight communication path was free from obstacles. 


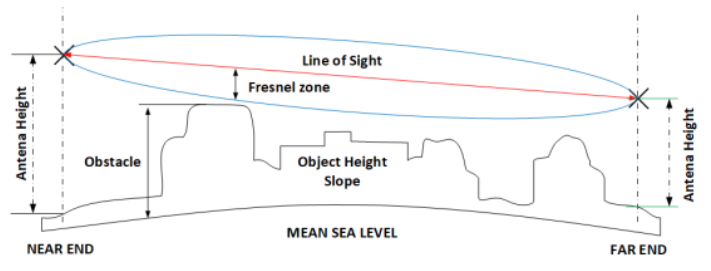

Figure 2. Results of determination of antenna height analysis

\section{METHOD}

The steps in designing the obstacle height monitoring system in microwave communication path were:

1. Collecting data on microwave radio transmission survey requirements related to determining the antenna height of the transmitterand the receiver and the height of an obstacle that was expected to interfere the line of sight communication system as a reference for the system design.

2. Collecting data on required specification and features related to measuring the height of the object on the communication path, the quadcopterfor carrying theobject height sensor, and the remote transmission system of the measured object height data to the monitoring location.

3. Designing and developing the obstacle height monitoring system.

4. Calibrating the instrument of object/obstacle height measurement by Laser Rangefinder.

5. Testing the developed system by measuring the height of an object/obstacle in the planned communication path and displayed the result in graphs in real time.

The study result was a tool for surveying the line of sight microwave radio transmission, which is mainly used to determine the height of an obstacle in the communication path. The obstacle height then used as a reference to determine the antenna height. Therefore, the secondary data were based on the survey requirement of the obstacle height monitoring system reference as follows [2][3].

1. The transmitter and receiver antenna in the radio communication system should be in a line of sight, with the height higher than the obstacle but lower than $40 \mathrm{~m}$ (AGL) in a suburban, urban, and dense urban areas or $70 \mathrm{~m}(\mathrm{AGL})$ in a rural area.

2. The conducted radio transmission survey is used for data transmission between BTS in a distance ranges from 1 to $1.5 \mathrm{~km}$ as the long distance communication system has used the optical fiber system nowadays.

The secondary data affected the selection of components/devices used in the obstacle height monitoring system as follows.

\section{Height sensors}

The height sensor must be light, small, and can reach the object size in the $100 \mathrm{~m}$ high range (AGL).This study used the Rangefinder type sensors with the specifications [4][5], as described in Table 1.

Table 1.Specification of rangefinder object height sensor

\begin{tabular}{|c|c|}
\hline Description & Data \\
\hline Distance & $5-600$ meter \\
\hline Wavelength & $905 \mathrm{~nm}$ \\
\hline Accuracy & $+/-0.5 \mathrm{~m}$ \\
\hline Operating Voltage & $5 \mathrm{~V}$ to 6 V \\
\hline
\end{tabular}

\section{Data Transmission Devices}

The resulting obstacle height data were transmitted through a wireless transceiver, which were then received at the monitoring location to be processed and displayed in real time. This study used $5.8 \mathrm{GHz}$ wireless transmission in the type of AV Transceiver TS 832 and RC 832, with a minimum power of $600 \mathrm{mWatt}$ and a distance range of $5 \mathrm{~km} \mathrm{[6].}$

\section{FSKModem}

The digital data generated by the height sensor were transmitted through a wireless transceiver that requires analog input. Therefore, a digital to analog data converter was used, which was an FSK modem with the type of TCM 3105 NE [7].

\section{Height Monitoring System Design}

After selecting the main components and devices forming the object monitoring system as a candidate obstacle, then the system was designedas the block diagram in Figure 3.

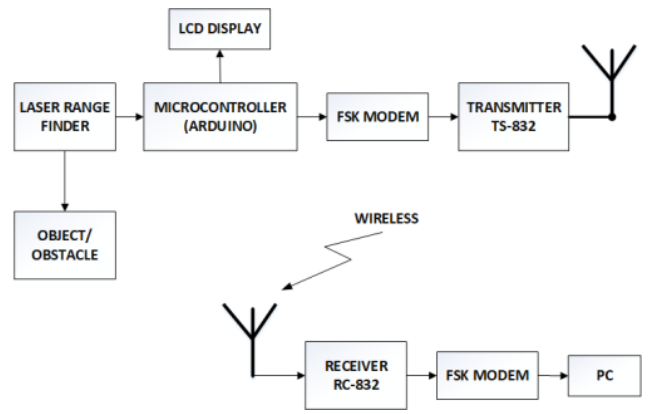

Figure 3. Block diagram of obstacle height monitoring system 


\section{Obstacle Height Measuring System}

The laser rangefinder height sensor was controlled by a microcontroller (Arduino Uno R3), then the generated height data were fed to the FSK modem to be transmitted to the monitoring location via the wireless AV Transceiver.

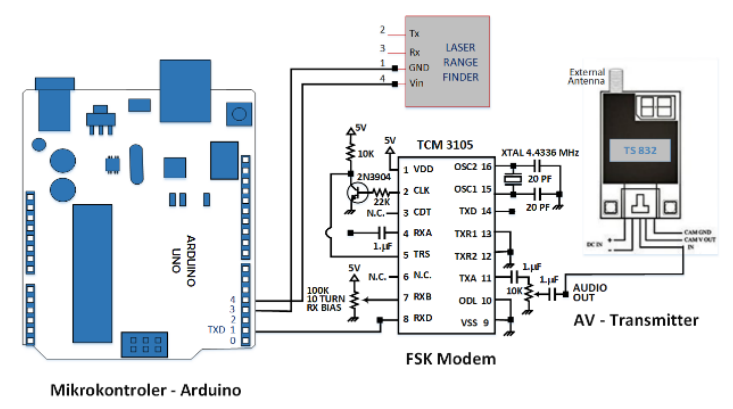

Figure 4. Obstacle height sensor control circuit

\section{Obstacle Height Data Receiver System}

The system in the monitoring location consists of an RC-832 wireless receiver, FSK modem, and computer to display height in real time in the form of graphs.

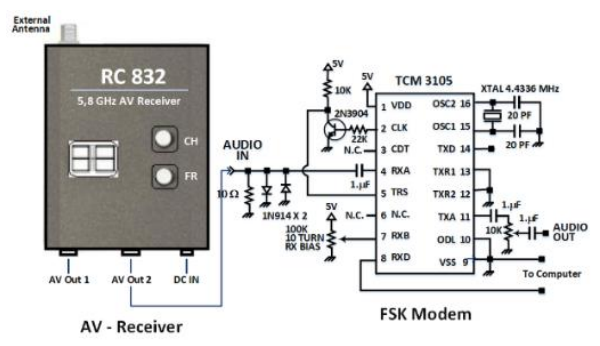

Figure 5. Obstacle height data receiver system

\section{RESULTS AND DISCUSSION}

The result of this study was an artificial model of an obstacleheight monitoring system on the line of sight of a microwave communication link using a quadcopter[8], as shown in Figure 6.

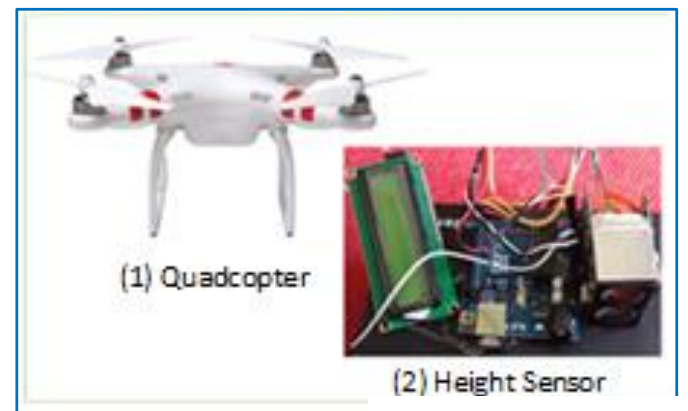

Figure 6. Obstacle Height Monitoring System
Obstacle height measurement is done using a laser rangefinder, was an electronic distance meter measuring instrument that is very well known for distance/ height measurement [6]. A laser rangefinder can also be used for robot motion sensors. This sensor is very precise [10]. So that this sensor was chosen and was very suitable to be used for obstacle height measurements in this study, although it has some disadvantages [9], were:

a. The laser rangefinder was Planar, which means that objects that were parallel to this sensor cannot be detected.

b. The Laser rangefinder cannot detect objects of a transparent type of material (for example; from glass materials).

c. Measurements on dark and very far objects have lower accuracy.

Apart from laserfinder deficiencies, the laser rangefinder was a high measurement sensor that was very efficient and accurate.

\section{Calibration of Height Sensors}

To ensure the implementation of the rangefinder as planned, the sensors were calibrated. The laser rangefinder calibration results for a constant distance of 220 meters, as shown in Figure 7.

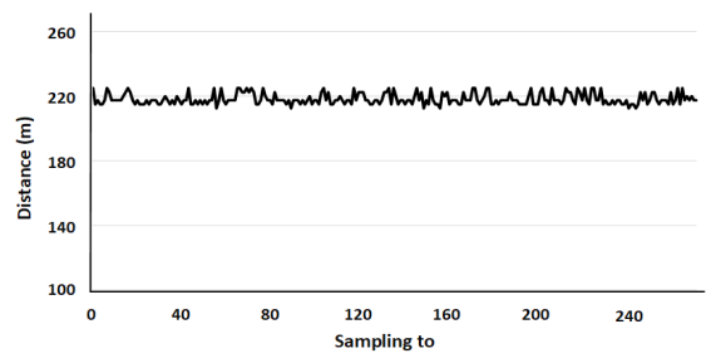

Figure7.Laser Rangefinder Calibration results

The calibration result shows that in 260 measurements of an object located in a distance of $220 \mathrm{~m}$, the average difference between the measured and the real distancewas $3.5 \mathrm{~m}$. This means that the error of the laser rangefinder device was $1.59 \%$ or it had an accuracy of $98 \%$.

Testing of Obstacle Height Monitoring System

To ensure the performance of the height obstacle monitoring system on the communication path between the near and far end, the system was tested with a planned track pathon the google map, as displayed in Figure 8. 


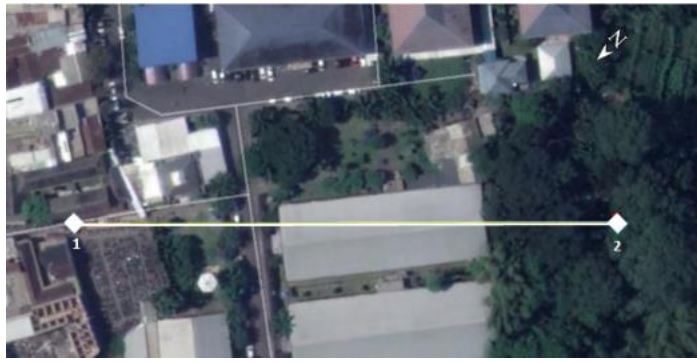

Figure8. The testing path of the rangefinder

The results of the obstacle height monitoring system are displayed in Figure 9.

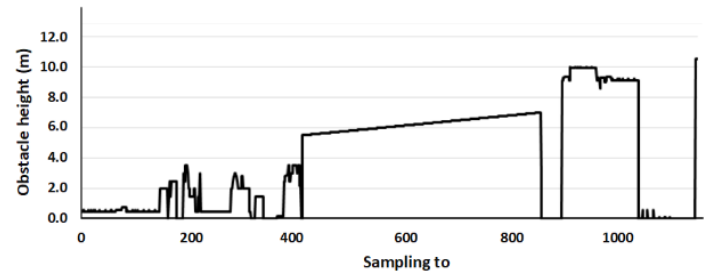

Figure 9. Graph of obstacle height measurement results

When the laser rangefinder sensor hit leaves or a tree, the measurement results were not stable because some laser beamshit the object underneath or through the leaves. The highest obstacle between communication links was 10.5 meters in the far-end location.

System testing data results were then used as a basis for determining the antenna height so that the communication link was free of obstacles. Using the Pathloss-4 software, the antenna height was determined [1], as shown in Figure 9.

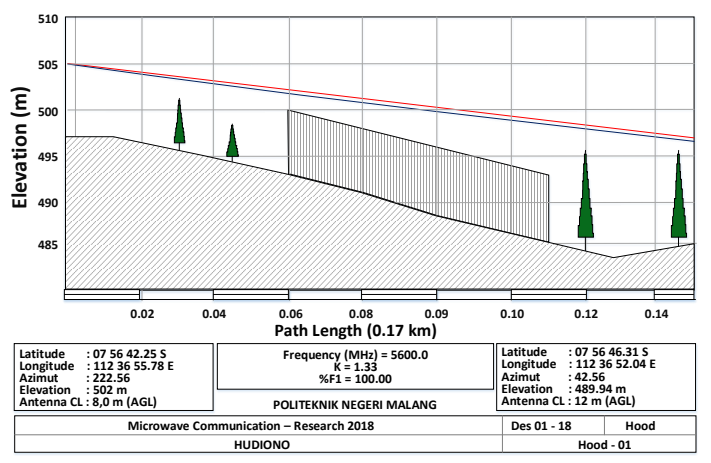

Figure 10. Determining the antenna height using Pathloss-4Software

Assuming the communication link had a WiFi frequency of $5.6 \mathrm{GHz}$, Fresnel of $100 \%$, and the value of $K=1.33$, then a communication link that was free of obstacle required the minimum antenna height at the near-end and far-end of 8 $m(A G L)$ and $12 m(A G L)$, respectively.

\section{CONCLUSION}

1. The laser rangefinder sensor has a maximum measurement specification of 600 meters andit can detect most types of objects, except for transparent objects or the materials that cannot reflect the laser beam.

2. The output of the height monitoring system is displayed in graphs; thus, it is easy to read without having to analyze it first.

3. Quadcopter that carriedthe monitoring system moved on the line of communication links as planned from the near-end location with coordinates of 0756 42.25 South and 1123655.78 Eastto the far-end location with coordinates of 0756 46.31 South and 1123652.04 East. The distance was 170 meters and the quadcopter flew above the height of the obstacle, which was 11.5 meters (AGL).

\section{ACKNOWLEDGMENT}

We would like to express our gratitude to:

1. Drs. AwanSetiawan, MMT., MM., the director ofPoliteknikNegeri Malang.

2. Dr. Eng. AnggitMurdani, S.T, M.Eng. Commitment Making Officer I, PoliteknikNegeri Malang.

3. ErfanRohadi, S.T., M. Eng, Ph.D., Director of Center of Community Service

4. Lecturers in the Department of Electrical Engineering, Study Program of Digital Telecommunication Network, PoliteknikNegeri Malang.

\section{REFERENCES}

[1]. Khan, Mohammad A.R., et al., (2015). Analysis for identify the problems of microwave installations and Solutions. IJRCCT, Vol 4, Issue 1, pp. 1-8

[2]. Kiema, J. B. K., Siriba, D. N., Ndunda, R., Mutua, J., Musyoka, S. M., \& Langat, B. (2011). Microwave Path Survey Using Differential GPS. Survey Review, 43(323), 451-461. doi:10.1179/003962611x131177488917

[3]. J. B. K. Kiema, D. N. Siriba, R. Ndunda, J. Mutua, S. M. Musyoka\& B. Langat (2011) Microwave Path Survey Using Differential GPS, Survey Review, 43:323, 451-461, DOI: 10.1179/003962611X13117748891796

[4]. De Floriani, L., Marzano, P., \&Puppo, E. (1994). Line-of-sight communication on terrain models. International Journal of 
Geographical Information Systems, 8(4), 329-342. doi:10.1080/02693799408902004

[5]. ShenZhenRuiEr Xing Electronic Co.,Ltd. (2011). Laser Works 600m LRF laser Rangefinder RS232 interface distance sensor laser distance module. Retrieved from https://www.laserexplore.en.alibaba.com/pr oduct-detail/Laser-Works-600m-LRF-laserrange finder 60504979219.html

[6]. Gleeson, Jarrad (2016). Remotely operated telepresent robotics. University Of Southern Queensland. USQ ENG4112 Research Project. Retrieved from http://eprints.usq.edu.au/id/eprint/31411

[7]. Campbell, Robert F. (2016). Analysis of Various Algorithmic approaches to SoftwareBased 1200 Baud Audio Frequency Shift Keying Demodulation for APRS. Master's Theses and Project Reports. Retrieved from https://digitalcommons.calpoly.edu/theses/ 1634

[8]. Jalali, A. (2014). Broadband access to mobile platforms using drone/UAV. United States Patent Ser. No . : $14 / 222,49$. Filed Mar. 21, 2014.

[9]. Siegwart, R., Nourbakhsh, I.R. (2004). Introduction to Autonomous Mobile Robots. Massachusetts Institute of Technology, ISBN13 978-0-262-19502-7.

[10]. Duchoň, F., Dekan, M., Jurišica, L., Vitko, A (2012). Some Applications of Laser Rangefinder in Mobile Robotics. CEAl, Vol.14, No.2, pp. 50-57. 